\title{
La reflexión ético-filosófica como ingrediente esencial en los nuevos planteamientos sobre el desarrollo sostenible: una propuesta para un curso universitario
}

\section{Introducción}

Vivimos una época de grandes retos a nivel planetario. Desde hace algunas décadas ha venido surgiendo una nueva sociedad global que, basada en las tecnologías de la información y las comunicaciones, abre posibilidades de desarrollo inimaginables. Sin embargo, al mismo tiempo nos encontramos ante una doble crisis, una de carácter medioambiental y otra relativa a la concepción que tenemos de nosotros mismos como seres humanos.

En lo que respecta a nuestra relación con la naturaleza, ya hace tiempo que la humanidad se ha dado cuenta del deterioro ambiental que nuestros procesos productivos y económicos están generando. Sin embargo, las inercias existentes nos han colocado en una situación complicada, casi en lo que parece un callejón sin salida. Así, después de algún tiempo de tratar de atacar solamente los síntomas de dicha degradación, en diferentes espacios de reflexión se empieza a tomar conciencia de que es necesario ir al fondo de la cuestión, es decir, buscar las causas profundas de esta crisis y cambiar nuestra concepción de naturaleza como cosa dominada por el hombre, concepción que proviene de diferentes herencias culturales.

Por otro lado, en lo que se refiere a la condición humana, ante la lógica capitalista del mercado, el hombre se ve a sí mismo como mero consumidor, convirtiéndose en un esclavo del sistema que le impide desarrollar todas sus potencialidades. El mundo está lleno de pobreza, pero no solamente de pobreza material, sino de pobreza humana que nos ha llevado a un sentimiento de vacío y de falta de sentido. Sin embargo, también se pueden encontrar signos positivos que muestran un anhelo de alcanzar algo más allá que meros avances materiales, un ansia de paz, tranquilidad, justicia y convivencia sana.

Debemos de voltear nuestra mirada y pensar en los temas del desarrollo no solo en el sentido económico sino en el sentido humano más pleno. La humanidad se encuentra en una encrucijada, en una época de transición que en pocos años determinará las características de nuestro futuro compartido, a una escala global. $Y$ es que el hombre, al pretender dominar la naturaleza para ponerla a su servicio, se encuentra también ante una lucha con el interior de sí mismo que le impide alcanzar esa plenitud. En el mundo actual, en nuestra sociedad industrial, ahora tendiente a una sociedad del conocimiento, se han visto revertidos algunos de los ideales que nacieron con la modernidad. Hemos caído en una especia de trampa donde hemos sido despojados de los más altos valores y nos hemos vuelto esclavos de un sistema de 
mercado en donde todo está dispuesto en términos de un orden económico enajenante. Por eso, ahora es necesario estar atentos a nuevas propuestas de transformación que tomen en cuenta la libertad y la posibilidad de un desarrollo armonioso, luchando contra la opresión y las diferentes formas de dominación presentes en nuestras estructuras económicas, políticas y sociales.

En esta tarea deberán estar involucrados los diferentes actores sociales e instituciones para construir juntos un mejor futuro. Las instituciones educativas y las universidades en particular tendrán un papel fundamental por ser los lugares por excelencia para el cuestionamiento, la reflexión y las nuevas propuestas. Pueden ser, por tanto, el lugar donde los hombres y mujeres que van a forjar el futuro, enfrenten estas nuevas problemáticas ambientales y del desarrollo con un enfoque no meramente técnico, sino con el ingrediente humano, reconociendo sobre todo la dimensión axiológica de las mismas.

En las siguientes secciones se hará un breve recuento de los antecedentes que nos han llevado a las crisis que hemos referido, se discutirán nuevas líneas de pensamiento que buscan enfrentar dichas crisis y se concluirá con algunas propuestas para un espacio de reflexión académica.

\section{Orígenes, constitución e incongruencias de la modernidad}

A lo largo de la historia el hombre se ha reinventado en varias ocasiones. Si quisiéramos considerar las diferentes culturas del mundo, estos momentos cruciales de la humanidad serían incontables, pero si nos ubicamos en los elementos que construyeron la cultura occidental, podríamos pensar en tres momentos fundamentales: el descubrimiento de la racionalidad en la civilización griega, la adopción del cristianismo y la llustración con sus elementos que constituyeron el ideal de modernidad.

Reconocemos en la cultura griega mucho de nuestros orígenes culturales. Como nos lo recuerda Bertrand Russell (Russell, 1945: 3), mucho de lo que soporta una civilización había ya existido en lugares como Egipto y Mesopotamia, pero no es sino hasta los griegos que encontramos una serie de elementos que habían estado ausentes. Nos referimos al terreno específico de lo racional. Son ellos quienes por primera vez especulan libremente sobre la naturaleza del mundo y del hombre y sobre el sentido de la vida. Por primera vez el ideal del hombre va más allá de las conquistas territoriales y la creación de ejércitos e imperios, para cuestionarse el mundo a nuestro alrededor y abrir la posibilidad de crear un mundo basado en la razón y el pensamiento.

En lo que se refiere a nuestra segunda herencia cultural, podemos decir que aunque en su origen el cristianismo no tiene nada de occidental, mas tarde será el credo oficial en el imperio romano. Con el cristianismo, el hombre se convierte en partícipe de la divinidad, está formado a imagen y semejanza de Dios. Si Dios es el supremo monarca del universo, el hombre lo es de la tierra. Se puede interpretar, en la tradición judeo-cristiana, a partir de las fuentes bíblicas, que Dios ha creado una jerarquía moral en la cual los humanos son superiores al resto de los seres vivos y han recibido el mandato de dominarlos. Después, en el siglo XIII, se funde la filosofía griega con la teología cristiana gracias al trabajo de Alberto Magno y más particularmente por obra de Tomás de Aquino quienes asimilaron la filosofía aristotélica a las creencias cristianas. 
Sin embargo, lo que dio lugar de manera más fundamental al hombre moderno es lo que se gestó en la revolución científica del siglo XVII y en la llustración y en las revoluciones burguesas del siglo XVIII que dan lugar a una transformación del ser humano que además de permanecer en el mundo quiere dominar el mundo. Algunos elementos que caracterizarán a este nuevo ser humano son el pensamiento formal, una mentalidad funcional y motivaciones morales auténticas, no impuestas. El resultado de esto será por un lado la creación del estado moderno y por otro el predominio de la ciencia, la tecnología y el mercado. Además, según Walter Beller hay tres nociones fundamentales en este proceso, que son libertad, individualismo e igualdad jurídica, las cuales,

[...] fueron las condiciones necesarias del pensamiento de la modernidad; constituyen tres elementos fundamentales de la visión del mundo que creció con la burguesía europea y que ésta llevó hasta sus últimas consecuencias. Lo interesante es que tales ideas encontraron también expresión en otros dominios de la vida cultural de la modernidad. Una de esas expresiones la encontramos en el racionalismo cartesiano Beller, 1991: 63).

Y es que efectivamente hay un redescubrimiento de la racionalidad que ya había sido ampliamente desplegada por los griegos, y que podemos rastrear en autores como Francis Bacon y René Descartes. En su esfuerzo por encontrar un método riguroso, asentado sobre bases indiscutibles, que lo llevara a un conocimiento cierto, Descartes desemboca en una filosofía que se ocupa de la racionalidad ideal, dejando de lado las racionalidades contingentes, concretas. Algunos autores, sobre todo de los llamados posmodernos sitúan aquí el origen de muchos de los males de nuestra civilización. Ven en este aislamiento de la razón pura una fragmentación de la misma, que yendo paralela al intento de dominación de la naturaleza, produce una separación del 'yo', creando un sujeto consciente, racional, tendiendo a ser libre. La característica de este ser racional es analizar, controlar, dominar a lo que está fuera de sí mismo. Para Bacon es un imperativo "que el género humano recobre su imperio sobre la naturaleza, que por don divino le pertenece" (Bacon, 1620-1991: 85). Pero en este proceso, este ser racional termina por incluir en este proceso de dominación al mismo sujeto humano, convirtiéndose así en víctima. De esa manera, la modernidad es testigo de una "disolución de un continuo de racionalidad que había unido al observador del mundo con el mundo" (Luhmann, 1997: 51-56). Así, el hombre, en su búsqueda de autonomía individual, pierde la garantía de unidad y certidumbre de la visión del mundo.

En este proyecto de modernidad gestado en los siglos XVII y XVIII, se encuentran muchas cosas positivas, sin embargo, también ha dado lugar a ciertos caminos torcidos o fallidos. Es decir, hemos transitado por un camino que nos ha llevado a tiempos en que el ser humano se ha visto sometido a un conjunto de poderes de carácter tecnoeconómicos que pretenden legitimarse en la razón científica, no dejando espacio a una racionalidad ampliada. Se trata de la conformación de un mundo en el que la capacidad y acción humanas son minimizadas a esferas de puro trabajo técnico bien organizado, de efectividad administrativa para el logro de intereses particulares; en una palabra, una forma de vida que al final deja vacío el espíritu humano y que además en los últimos tiempos, ha venido produciendo una degradación ambiental de consecuencias fatales.

Podemos ahora extender estas ideas sobre la constitución de la modernidad, pero en términos de los principios éticos que han sido dominantes. Nos referimos a las orientaciones éticas utilitaristas y deontológicas. En cuanto a la tradición utilitaria podemos decir que se desarrolla bajo el principio de maximizar el bien total o producir el máximo bien para el mayor número de personas. Pero el bien para las personas sería el placer o la felicidad, entendida ésta como que la gente tenga lo que desea. Estas ideas se 
pueden conectar con la teoría económica de libre mercado en donde esos deseos y preferencias se expresan en el mercado económico por la voluntad de pago de los individuos. No es difícil darse cuenta de que los razonamientos de carácter utilitario han sido especialmente influyentes en las áreas de la economía, de las políticas públicas y de las regulaciones gubernamentales, lo cual significa que el utilitarismo ha jugado un papel importante en el tema de las políticas ambientales (Des Jardín, 2001: 26).

Las éticas deontológicas, a diferencia de las utilitaristas, no se ocupan del bien, sino del deber ser (Cortina y Martínez, 2001: 71-75). La referencia obligada aquí es Kant, quien nos habla de los imperativos categóricos como los mandatos que deben cumplirse por si mismos, sin someterlos a condiciones ulteriores. La regla que determina dichos mandatos sería la de actuar solamente en la forma en que todos los seres racionales encontrarían aceptable y universalizable, o en términos más coloquiales, "no hagas a otros lo que no quieras que te hagan a ti". Estos planteamientos son de especial importancia en el tema de la justicia que, por un lado nos exige cumplir nuestros deberes para con otras personas, y por otro nos concede el derecho a ser tratados dignamente. Una de las limitaciones principales de este tipo de orientación ética es que deja poco lugar para las obligaciones hacia cualquier cosa que no sea libre o racional.

Ambas tradiciones, la utilitarista y la deontológica, han sido especialmente influyentes en el desarrollo de nuestras formas de gobierno y de nuestras instituciones sociales, en donde uno de los objetivos ha sido dotarlas de la capacidad de ofrecer fuertes protecciones a las libertades y los derechos individuales. Y estas instituciones, a su vez, en un proceso circular, crean y forman nuestras actitudes, creencias y valores. Cabría preguntarnos si esta conformación social que se reproduce a través de nuestras instituciones promueve la cooperación y la vida en comunidad, o más bien refuerzan la competencia y la dominación, y si impulsa el aprecio por nuestro medio ambiente o favorece un comportamiento de poco compromiso con nuestro entorno. Desgraciadamente, las respuestas a estas preguntas, si nos atenemos a las evidencias, se inclinan más hacia las segundas opciones indicadas.

Buscando de esta manera en el pasado algunos elementos clave de la constitución de nuestra cultura occidental, nos hemos encontrado con diferentes tradiciones, tanto de origen religioso como científico y filosófico, que nos han alentado a vernos a nosotros mismos como seres superiores, justificando de esta manera nuestro derecho al dominio de la naturaleza. Hemos construido la idea de que nos pertenece un status especial en este mundo, como seres separados de la naturaleza y que la trascienden.

¿Podemos corregir nuestros errores y atender nuestros problemas ambientales y de desarrollo sin abandonar completamente la visión del mundo y de nosotros mismos que hemos venido construyendo, o es necesario un cambio radical? Algunos autores apuntan a la necesidad de esto último. No compartimos completamente esta idea de tirar por la borda lo que nos ha tomado años para constituirnos como hombres modernos, sin embargo, debemos atender y analizar algunas propuestas recientes sobre la necesidad de construir nuevos elementos de ética ambiental y de ética del desarrollo.

\section{Ética ambiental}

De las secciones anteriores, sale a la luz el hecho de que las tradiciones filosóficas occidentales parecen negar que haya alguna relación moral entre los seres humanos y la naturaleza. Las propuestas de "desarrollo sustentable" típicamente se mueven dentro del mismo orden económico reinante, con la 
salvedad de que intentan incorporar en sus propuestas mecanismos para aliviar el deterioro ambiental, pero en ellas subyacen las mismas filosofías utilitarias a que nos hemos referido.

En los últimos años, pensadores que son más radicales desde una perspectiva filosófica, han argumentado que sí hay responsabilidad ética hacia la naturaleza mas allá de un mero cuidado de la misma para nuestro propio provecho, es decir, una responsabilidad que no depende de las consecuencias hacia los hombres. Las propuestas son muy variadas. Aquí nos referiremos a dos de ellas, una de carácter específico denominado biocentrismo y otra de carácter mas general, como un grupo de propuestas a las que se les conoce bajo el rubro de ecología profunda (deep ecology).

A la ética atañe la reflexión en torno a la responsabilidad hacia otros y a los derechos que podemos esperar ejercer. Las éticas tradicionales, sobre todo las de carácter utilitarista y deontológico limitan esta relación a la que se da entre seres humanos, no atribuyendo status moral a otros tipos de entidades. Kant, por ejemplo, establecía que nuestros deberes hacia la naturaleza son indirectos, es decir, en realidad son deberes para con otros seres humanos. La ética biocéntrica, por el contrario, se basa en asignar un valor intrínseco a la vida (Des Jardín, 2001: 135). Desde esta perspectiva cualquier ser vivo merece la misma consideración, bajo un principio de reverencia por la vida. Los críticos de estas posturas hacen una caricatura de ellas como románticas e ingenuas, pues es difícil comprender que tengan el mismo valor un ser humano y un microbio. Después de todo, para mantener la vida, otras vidas deben sacrificarse como comida. Pero no se trata de eso, sino que es una cuestión de actitud de máxima consideración hacia la vida, como virtud moral que nos hace mejores seres humanos. $Y$ aunque ciertas normativas deban en un momento derivarse de estas posturas, el asunto principal no es la forma de acción específica que debemos asumir en ciertas situaciones, sino la perspectiva sobre el tipo de personas que deseamos ser, la nueva visión que debemos tener sobre nosotros mismos.

Paul Taylor es uno de los autores que hacen una defensa más completa del biocentrismo. Para explicar qué entidades merecen nuestra consideración por poseer un valor intrínseco, Taylor utiliza el concepto de centro teleológico de la vida. Cualquier ser vivo o la vida misma es direccional, manifestándose esto en los procesos biológicos de crecimiento, desarrollo, propagación y sostenimiento de la vida. Todos los seres vivos somos miembros de una comunidad de vida en la Tierra, somos parte de un sistema interdependiente y por lo mismo los seres humanos no somos inherentemente superiores a otros seres vivos. Esta es la posición central, consistente en enfatizar el valor de todo ser vivo. Sin embargo, es claro que este tipo de posición es muy radical y deja muchas preguntas sin responder: ¿es este valor de la vida verdaderamente un valor moral o un tipo diferente de valor, probablemente aún de tipo antropocéntrico? ¿qué sucede cuando el interés de la vida humana entra en conflicto con el interés de otros seres vivos?

Las posturas ético ambientalistas a que estamos haciendo referencia son difíciles de entender porque representan un giro completo sobre la visión de lo que somos. Esto es especialmente cierto respecto al concepto de Ecología Profunda. Esta idea se usa de muchas maneras y está asociada a movimientos que se oponen deliberadamente a las instituciones sociales que nos rigen y que pugnan por principios y creencias alternativas. Aquí nos referiremos fundamentalmente al enfoque desarrollado por Arne Naess. Según éste y George Sessions, los principios básicos de la ecología profunda son:

1) El bienestar y el florecimiento de la vida humana y no humana en la Tierra tienen valor en sí mismos. Estos valores son independientes de la utilidad del mundo no humano para los objetivos humanos. 2) La riqueza y diversidad de las formas de vida contribuyen a la percepción de estos valores y son también valores en sí 
mismos. 3) Los humanos no tienen derecho a reducir esta riqueza y diversidad, salvo para satisfacer necesidades vitales. 4) El florecimiento de la vida y cultura humanas es compatible con un descenso sustancial de la población humana. El florecimiento de la vida no humana requiere este descenso. 5) La interferencia humana actual en el mundo no humano es excesiva y la situación empeora por momentos. 6) Por lo tanto, deben cambiarse las políticas. Estas políticas afectan a las estructuras económicas, tecnológicas e ideológicas básicas. El estado de cosas resultante será profundamente diferente del presente. 7) El cambio ideológico consiste fundamentalmente en apreciar la calidad de vida (vivir en situaciones de valor inherente) más que adherirse a un nivel de vida cada vez más alto. Habrá una profunda conciencia de la diferencia entre grande y excelente. 8) Quienes suscriben los puntos precedentes tienen la obligación directa o indirecta de tratar de llevar a cabo los cambios necesarios (citado en Castells, 1999: 141).

La afirmación primaria que encontramos en los propulsores de la ecología profunda consiste en que la crisis ambiental actual tiene sus raíces en causas filosóficas profundas, y por lo mismo el remedio solo se puede encontrar en un cambio radical de nuestra perspectiva filosófica. En este sentido, la ecología profunda es una crítica de la visión del mundo dominante en nuestras sociedades y nos invita a reconsiderar preguntas metafísicas como por ejemplo ¿cuál es la naturaleza humana?, ¿cuál es la relación entre seres humanos y el resto de la naturaleza? ¿ ¿cuál es la naturaleza de la realidad? La idea principal que habría que cambiar es la que consiste en el carácter individualista y reduccionista de nuestra visión moderna de la realidad. Carácter individualista que por un lado nos hace vernos como separados de la naturaleza y que, en un sentido más amplio, confiere realidad solamente a los seres individuales (no solo humanos) y no al conjunto de las cosas; en este sentido el biocentrismo al que nos referimos antes sigue privilegiando esta visión que la ecología profunda rechaza. Y carácter reduccionista que esconde en muchos sentidos las profundas interrelaciones que existen en la naturaleza. La nueva idea defendida por la ecología profunda enfatiza que las cosas individuales (seres humanos, animales, plantas) son efimeras y lo que permanece son los procesos, los flujos de materia y energía, siendo las cosas individuales solo perturbaciones locales en este flujo universal de energía.

Las consecuencias éticas de esta escuela de pensamiento son muy importantes. Bajo esta perspectiva el bienestar humano no tendría prioridad moral. De acuerdo con los principios básicos enumerados anteriormente, los humanos tendrían derecho a reducir la riqueza y la diversidad natural solamente para satisfacer las necesidades vitales más básicas. Algunos críticos de estas corrientes las consideran como una ideología Americana tendiente a decirles a los países pobres que ya se han experimentado las consecuencias del desarrollo y que ahora ellos (la gente de los países pobres) deben evitar el deterioro de la naturaleza aún si tienen que vivir a niveles de mera subsistencia.

Creemos que sería éticamente repulsivo una perspectiva ambiental que desatendiera las necesidades humanas, en todo caso, lo que sería aceptable sería reformular estas últimas. Las nuevas éticas del desarrollo se ocupan de estos temas.

\section{Ética del desarrollo}

Los últimos párrafos nos conectan con el tema del desarrollo de las personas y de los pueblos, que entenderemos en el sentido de proceso que permite el despliegue de las capacidades humanas, tanto físicas como culturales, políticas y económicas. Además de esto, es importante agregar la consideración de que todos (individuos, comunidades, naciones) vivimos en un mundo lleno de interrelaciones e 
interdependencias en el que un buen desarrollo nunca puede ser a costa de perjuicios para otros o para el planeta en el que vivimos y que compartimos.

Desde estos puntos de vista es fundamental hacer la distinción entre crecimiento económico y desarrollo. Según nos explica el filósofo Emilio Martínez (2000: 51), aunque en muchas ocasiones se han usado estos términos como equivalentes, sobre todo en el discurso oficial de muchos gobiernos, la diferencia, que debe ser clara después de ser testigos de lo que sucede en muchos países, consiste en que el crecimiento económico, que suele medirse por medio del Producto Interno Bruto, se refiere solo al aumento de la producción total de bienes y servicios de un país, en tanto que el buen desarrollo humano tiene que ver con una distribución equitativa de la riqueza, pero no solo eso, sino que abarca todas las dimensiones económica, biológica, psicológica, cultural y espiritual de las personas. La idea limitada de crecimiento económico para proveer de satisfacciones materiales reduciría al mínimo la condición del ser humano, probablemente identificando la felicidad con el consumo, y no tomaría en cuenta las diferentes características geográficas, históricas y culturales que presentan los pueblos, las comunidades o las naciones. $Y$ es que las personas y/o comunidades son únicas y por lo tanto deben tener la opción de perseguir fines diferentes, y lo que requieren es que se cumplan una serie de condiciones que permitan su plena realización. Por eso según Sergio Boisier,

[...] hoy el desarrollo es entendido como el logro de un contexto, medio, 'momentum', situación, entorno, o como quiera llamarse, que facilite la potenciación del ser humano para auto transformarse en persona humana, en su doble dimensión, biológica y espiritual, capaz en esta última condición, de conocer y amar. Esto significa reubicar el concepto de desarrollo en un marco [...] valorativo o axiológico [...] y por tanto será inútil asociarlo con meros avances materiales [...]" (Boisier, 2001: 29).

De ahí que la dimensión ético-filosófica cobre vital importancia para enfatizar la noción humanista del desarrollo. Bajo esta perspectiva, el desarrollo estará centrado en la persona y su posibilidad de alcanzar plena dignidad ejerciendo todas sus facultades, sobre todo la racionalidad, pero bajo una perspectiva amplia. La racionalidad deberá ser entendida no solamente en su dimensión científico técnica, por más que este ámbito haya alcanzado mayor protagonismo en nuestras sociedades occidentales, sino también en su dimensión dialógica y en su dimensión práctico-moral. La racionalidad meramente técnica tiene como objetivo conseguir un fin concreto, aplicando la lógica dura y el conocimiento científico, usando los recursos disponibles de modo instrumental. En cambio, la racionalidad ética busca promover ciertos valores por sí mismos y opera con una lógica diferente. Esto es fundamental si hemos de creer en el valor de que las personas participen en los proyectos de desarrollo de sus comunidades con la capacidad de llegar dialógicamente a soluciones éticas aceptables para todos.

Carlos Rojas (2001) nos explica que las tareas del desarrollo se deben llevar a cabo bajo la perspectiva de una racionalidad comunicativa que valore no solamente la lógica y la ciencia, sino también las tradiciones culturales, la comunidad, el medio ambiente, el sentido de identidad y pertenencia y el reconocimiento de diferentes sistemas de valores. Denis Goulet nos hace ver, con su experiencia participando en proyectos de desarrollo, que,

[...] los problemas surgen porque cada racionalidad tiende a tratar a las demás de modo reduccionista, intentando imponer su punto de vista particular sobre los fines y procedimientos, durante todo el proceso de toma de decisiones. Las decisiones resultantes pueden ser técnicamente correctas pero repulsivas éticamente; en otros casos pueden ser éticamente válidas pero técnicamente ineficientes [...]. (Citado en Martínez, 2000: 47). 
Por eso es fundamental la cooperación efectiva entre diferentes saberes y enfoques al servicio de un objetivo común. Para la consecución de un proyecto concreto de desarrollo se debe atender a una multiplicidad de racionalidades, discursos y sistemas de valores.

Rojas (2001) sugiere que los expertos en planificación para las tareas del desarrollo deben ser capaces de actuar como mediadores y negociadores, a través de una participación activa que busque balancear, sobre bases éticas, los diferentes puntos de vista de los afectados e interesados. Es decir, las funciones de planeación no deben ser relegadas solo a los "expertos", sino que los aspectos científicos y tecnológicos deben ser enriquecidos por la discusión de los dilemas morales involucrados bajo un principio de comunicación equitativa. Solo de esta forma se respetará la dignidad de la persona, base fundamental de un buen desarrollo, pues como lo menciona Martínez (2000),

En el ámbito de las tareas del desarrollo, las personas afectadas -todas ellas- son dignas de participar activamente en todas las fases de realización de dichas tareas, y negarles la oportunidad de hacerlo o no poner los medios para que desarrollen su capacidad de participación es tratarlas como cosas, como objetos manipulables (Martinez, 2000: 60).

\section{Replanteando la condición del ser humano}

Hemos insistido en la necesidad de una mirada ético-filosófica a los problemas medioambientales y del desarrollo. Esta perspectiva nos permite identificar los temas de verdadero interés humano, nos guía en el proceso de clarificar y analizar la multiplicidad de argumentos y racionalidades que los diferentes actores llevan al debate y, en suma, representa un apoyo fundamental.

Queremos proponer una visión más integral y balanceada de los temas que hemos presentado hasta este momento. No se trata de sustituir una racionalidad económica por otra ecológica, sino de enriquecer ambas visiones. Tenemos una herencia de varios siglos de lucha en búsqueda de libertad e igualdad que nos ha llevado a nuestro reconocimiento como individuos y poseedores de una verdadera dignidad humana. Hemos construido una tradición liberal que nos habla de derechos humanos, pluralismo, libertad de expresión, igualdad de oportunidades; conceptos todos que nos resultan, y con razón, irrenunciables. No podemos, ni debemos, hacerlos a un lado en pos de alguna visión radical que nos despoje de esos logros al, por ejemplo, renunciar al desarrollo en una malentendida defensa de la naturaleza. Pero, por otro lado, debemos reconocer que los logros citados y que deberían significar el logro de una vida mas plena y llena de significados, los hemos convertido en ocasiones en aislamiento, desarraigo y egoísmo; en una pérdida de vida en comunidad.

No debemos renunciar a la visión de ser humano que hemos construido, sino que solamente debemos corregir parte del camino andado y reconocer que en nuestras tradiciones se contienen ya las semillas de una relación éticamente apropiada con nuestro medio ambiente. Y cuando hablamos del medio ambiente deberíamos referirnos no solo al conjunto de cosas físicas (naturales o artificiales) que nos rodean, sino también al mundo de valores y de relaciones humanas que nutren nuestro espíritu. Todo, en su conjunto, es lo que nos puede brindar la posibilidad de desarrollar todas nuestras potencialidades humanas. 
La figura siguiente nos muestra los elementos que se requieren, según nuestro entender, para el logro de un desarrollo humano integral:

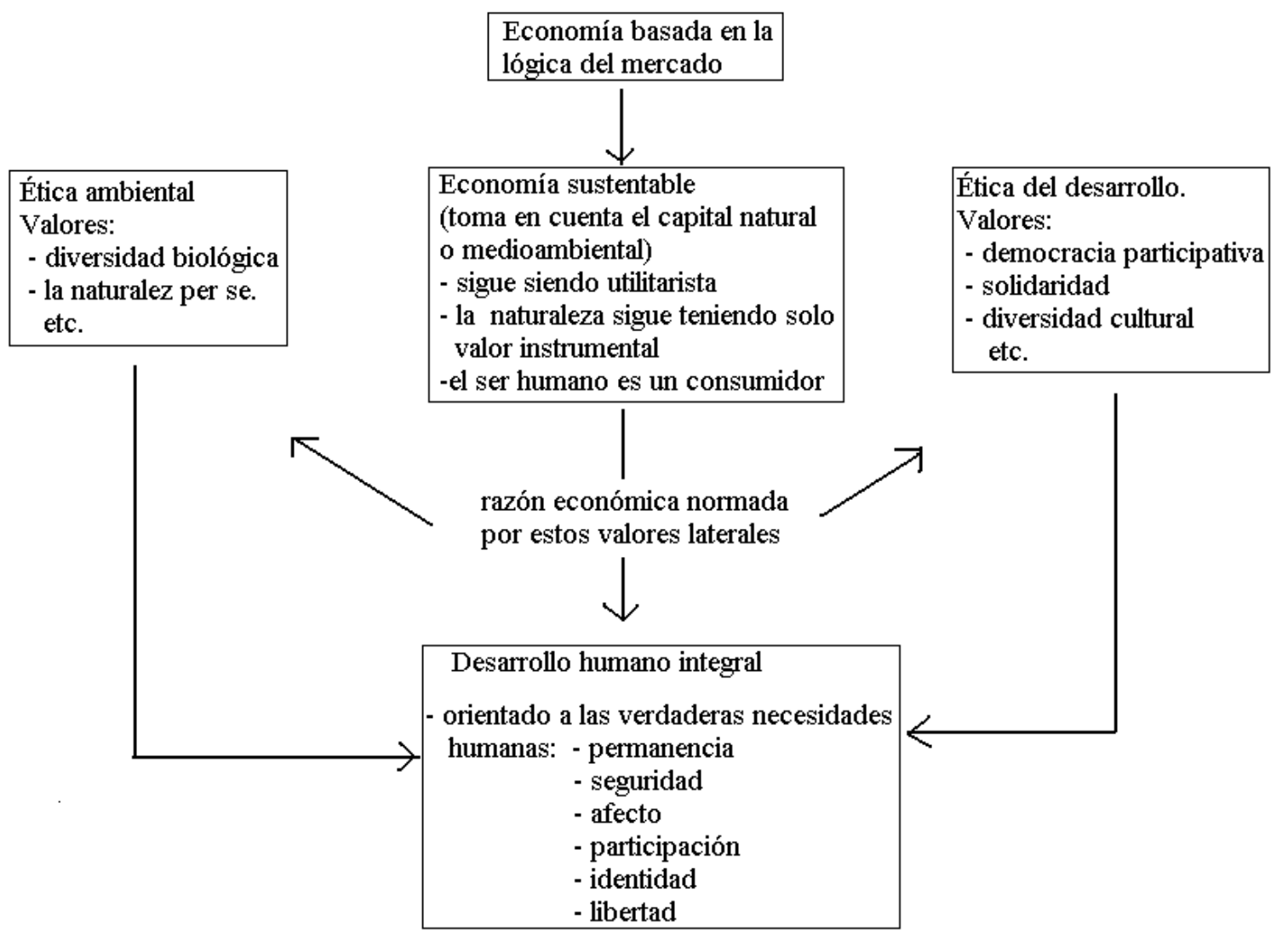

Pensando en una evolución a partir de la economía basada en la lógica del mercado que hemos heredado en nuestros sistemas capitalistas, vemos en esta figura un primer paso hacia una economía sustentable ante la evidencia clara de deterioro de los recursos naturales. Resulta claro que estos últimos no son infinitos y que tienen que considerarse como parte del cálculo económico en nuestros sistemas de producción.

Sin embargo, siguiendo con este esquema, la visión sigue siendo utilitarista pues la naturaleza sigue teniendo solo un valor instrumental, y lo que es más importante, solo consigue disminuir los síntomas de la crisis medioambiental, pero no enfrenta las causas estructurales. Es decir, no se dirige a la constitución moral del ser humano, el cual sigue siendo considerado un mero "consumidor". Por eso surgen una serie de propuestas en el campo de la ética ambiental por un lado, y la ética del desarrollo por otra que buscan una reflexión filosófica que vaya más a la raíz de la problemática humana: ¿qué somos? ¿cuál es nuestro propósito? ¿cómo debemos actuar, cuál es nuestra responsabilidad, no solo para con nuestros semejantes sino para con nuestro ambiente?

La propuesta es, finalmente, recoger los elementos de la razón económica necesarios para el desarrollo, pero normados, evitando adoptar posiciones radicales, por los valores que surgen de esa 
reflexión, para así lograr un desarrollo humano integral que se enfoque a las verdaderas necesidades humanas de permanencia, seguridad, afecto, participación, identidad, libertad, etc.

Existe una pluralidad de propuestas de ética ambiental y de ética del desarrollo. Se nos puede criticar por no favorecer o dar argumentos a favor de una en particular, es decir de no dar una respuesta objetiva al problema del medio ambiente y del desarrollo. Nuestra respuesta es que al pretender abordar estos temas con una perspectiva ética, precisamente nuestra intención es no caer en la mirada científica reduccionista de que una problemática tiene una única solución verdadera. La idea es privilegiar el diálogo y adoptar una especie de racionalidad comunicativa, que en condiciones adecuadas de equidad nos permita resolver nuestros problemas de desarrollo.

Por eso proponemos un pluralismo que reconozca la complejidad de los temas abordados y que integre la reflexión ética a la mesa de las discusiones. Si queremos privilegiar una participación democrática, debemos estar preparados para encontrar una gran variedad de perspectivas y valores.

\section{Una propuesta académica}

Edgar Morin nos dice en un brillante ensayo en el que argumenta sobre los saberes necesarios para la educación del futuro que ésta,

[...] deberá ser una enseñanza primera y universal centrada en la condición humana. Estamos en la era planetaria; una aventura común se apodera de los humanos donde quiera que estén. Estos deben reconocerse en su humanidad común y, al mismo tiempo, reconocer la diversidad cultural inherente a todo cuanto es humano (Morin, 1999: 21).

Tomando a manera de guía esta idea de Morin, trataremos de recapitular algunas de las ideas expuestas previamente, para de ahi generar algunas propuestas de carácter general para un curso que aborde los temas de la protección ambiental y del desarrollo humano. Entonces, considerando que:

1) Vivimos momentos históricos en los que hemos reconocido el carácter finito de nuestro planeta y sus recursos y se ha ido generando un cierto nivel de conciencia de que la actividad humana pone en peligro los equilibrios ecológicos.

2) Resulta ya insostenible la idea del desarrollo en el que solamente sobresale lo técnicoeconómico, y es necesaria una noción mas completa e integral que sea no solo material sino también intelectual, afectiva y moral, y sobre todo que sea compatible con la protección del medio ambiente.

3) Debe recuperarse la reflexión filosófica en el sentido de atención intelectual a los problemas humanos, pero en íntima conexión con los conocimientos científicos lla ciencia, hija de la filosofía, quedó huérfana en algún momento de la historia).

4) Es necesario practicar la ética de la comprensión y de la solidaridad dentro de la diversidad, pues "si sabemos comprender antes de condenar estaremos en la vía de humanización de las relaciones humanas" (Morín, 1999: 50). 
5) La ciencia sola no es suficiente para resolver nuestros problemas ambientales y de desarrollo, pues si bien es esencial para establecer los hechos, es de muy pobre ayuda para identificar los valores que le queramos impregnar a nuestras acciones.

6) La universidad representa el lugar por excelencia para el cuestionamiento crítico, en donde no se puede ni se debe inculcar un adoctrinamiento en valores específicos, pero sí promover la realización de valores sociales de carácter general requeridos para la salud e integridad de la misma sociedad, dentro de lo cual, la protección ambiental es un aspecto fundamental.

Nos parece relevante para todo estudiante universitario, independientemente de su área de especialización, un curso que reconozca los puntos anteriores, en el cual:

1) La intención educativa principal sea crear conciencia de la importancia de la protección ambiental y del desarrollo humano, reconociendo la complejidad del tema, como un asunto que debe ser visto y analizado desde múltiples perspectivas (económica, filosófica, ética, etc.), para evitar asi una visión estrecha y miope.

2) El objetivo fundamental sea que los estudiantes adquieran un conocimiento de diferentes propuestas actuales de ética ambiental y de desarrollo humano y adquiera las habilidades necesarias para ponderarlas y para analizar, con fundamento, casos que se le presenten para su discusión.

3) Se examine la influencia de las tradiciones culturales y las creencias dominantes en nuestras actitudes hacia el medio ambiente y se discuta la relevancia de teorías éticas, tanto tradicionales como de nuevas tendencias, en las decisiones ambientales y del desarrollo.

Los contenidos específicos y las técnicas de enseñanza aprendizaje podrían variar, pero se deberá privilegiar siempre el diálogo y la tolerancia en el proceso mismo de aprendizaje, para que eso mismo se incorpore como parte de los objetivos del curso.

\section{Bibliografía}

BACON, F. (1620-1991): Novum Organum, México, Editorial Porrúa.

BELLER, W. (1991): Libertad, igualdad y sujeto. En La revolución francesa: doscientos años después. Griselda Gutiérrez, compiladora. México, Facultad de Filosofía y Letras, UNAM.

BOISIER, S. (2001): Sociedad del conocimiento, conocimiento social y gestión territorial. Santiago de Chile. <www.fundicot.org/grupo\%207/011.pdfs.

CALLICOTT, J. B. (1996): Earth Summit Ethics: toward a reconstructive postmodern philosophy of environmnental education, New York, State University of New York Press.

CASTELLS, M. (1999): La Era de la Información: Economía, Sociedad y Cultura, vol II. México, Siglo XXI editores.

CELY, G. (1999): La bioética en la sociedad del conocimiento. Colombia, 3R Editores LTDA.

CORTINA, A., y MARTINNEZ E. (2001): Ética, Madrid, Ediciones Akal. S.A.

DES JARDIN, J. R. (2001): Environmental ethics: an introduction to environmental philosophy, Canada, Wadsworth/Thomson Learning. 
LUHMANN, N. (1997): Observaciones de la modernidad: racionalidad y contingencia en la sociedad moderna, Barcelona, Paidós.

MORIN, E. (1999): Los siete saberes necesarios para la educación del futuro, UNESCO.

ROJAS, C. (2001): Discourses of the environment. Tesis presentada en la Universidad de Cincinnati.

MARTÍNEZ, E. (2000): Ética para el desarrollo de los pueblos, Madrid, Editorial Trotta.

RUSSELL, B. (1945): A History of Western Philosophy, A Clarion Book, Simon of Shuster. 


\title{
Contactar
}

Revista lberoamericana de Educación

\author{
Principal OEI
}

